Endocrinol. Japon. 1987, 34 (6), 919-925

\title{
Self-Priming Effect of LH-RH on Pituitary Gonadotropins in Hyperprolactinemic Women
}

\author{
Tsunehisa MAKINO, Mamoru TAKAHASHI, KaZUKi FUKUOKA, \\ TAKASHI SEKI AND RIHACHI IIZUKA
}

\author{
Department of Obstetrics and Gynecology School of Medicine, \\ Keio University Tokyo 160, Japan
}

\begin{abstract}
To investigate how various concentrations of serum prolactin (PRL) influence the priming effect of luteinizing hormone releasing hormone (LH-RH) on the pituitary gland, 24 women with various blood PRL concentrations received intravenous injections of $100 \mu \mathrm{g}$ of synthetic LH-RH twice at an interval of 60 minutes and their serum $\mathrm{LH}$ and follicle-stimulating hormone $(\mathrm{FSH})$ were measured and analysed. In the follicular phase with a normal PRL concentration (PRL $<20 \mathrm{ng} / \mathrm{ml}, \mathrm{n}=6$ ), marked first peaks of the two hormones following the first LH-RH stimulation and enhanced second peaks after the second LH-RH administration were observed, indicating a typical priming effect of LH-RH on gonadotropins, though the second response of FSH was more moderate than that of LH. In hyperprolactinemia, in which the serum PRL concentration was higher than $70 \mathrm{ng} / \mathrm{ml}(\mathrm{n}=13)$, the basal concentration of gonadotropins was not significantly changed but the priming effect of LH-RH on LH and FSH was significantly decreased $(\mathrm{p}<0.01)$. No marked second peaks of LH and FSH were observed, suggesting an inhibitory effect of hyperprolactinemia on the second release of $\mathrm{LH}$ and FSH. In contrast, this effect was restored in a group of women whose serum PRL concentration was between 30 and $50 \mathrm{ng} / \mathrm{ml}(\mathrm{n}=5)$. Furthermore, enhanced second peaks of both LH and FSH were noted after successful bromocriptine therapy reduced hyperprolactinemia $(P R L>70 \mathrm{ng} / \mathrm{ml})$ to less than $25 \mathrm{ng} / \mathrm{ml}(\mathrm{n}=5)$. Statistical analysis of the first and second peak ratio $\left(\Delta_{1} \Delta_{2}\right.$ ratio) of $\mathrm{LH}$ and serum PRL concentration revealed that these two factors correlated well with each other $(r=0.9500)$. These data suggest that the priming effect of LH-RH can be utilized for the evaluation of the pituitary function of secreting gonadotropin in hyperprolactinemia.
\end{abstract}

Hypothalamic luteinizing hormone releasing hormone (LH-RH) acting on an anterior pituitary gland sensitized with ovarian steroid hormones may exert a priming effect on the pituitary gonadotrophs so that further

Received April 15, 1987 exposure to the hormone is followed by a marked increase in response (Padmanabhan 1982). Continuous infusion of LH-RH or intermittent stimulation with this decapeptide has been reported to induce similar first and second LH release in various species including the human female (Aiyer et 
al., 1974; Hoff et al., 1977; Lin et al., 1982). The second increased release of LH indicates that repeated stimulation with $\mathrm{LH}-\mathrm{RH}$ could assist in examining both the release and synthesis of the pituitary function.

The purpose of this study was to investigate how various levels of serum prolactin (PRL) influence the priming effect of $\mathrm{LH}-$ $\mathrm{RH}$ on the pituitary gland by stimulating women with LH-RH intermittently at 60 minute intervals, so that all subjects can be tested within a day for hypothalamic disorders.

\section{Subjects and Methods}

\section{Subjects}

Twenty-four women aged from 21 to 39 years were divided into three groups according to their serum PRL levels at 10 a.m.. The limits of the PRL concentrations in these three groups were (1) less than $20 \mathrm{ng} / \mathrm{ml}(\mathrm{n}=6)$, (2) between 30 and $50 \mathrm{ng} / \mathrm{ml}(\mathrm{n}=5)$, (3) more than $70 \mathrm{ng} / \mathrm{ml}(\mathrm{n}=13)$, respectively. All the women received intravenous injections of $100 \mu \mathrm{g}$ of synthetic LH-RH twice at an interval of 60 minutes on 7-10th day of the menstrual cycle or after the cessation of uterine bleeding induced by estrogen and/or progesterone injection intramuscularly. Blood samples were collected at $0,30,90120,180$ minutes after the first LH-RH stimulation. Five of 13 women with hyperprolactinemia were subjected to this 2 step LH-RH administration test after their serum PRL concentrations were reduced to less than $25 \mathrm{ng} / \mathrm{ml}$ by bromocriptine therapy $(2.5-50 \mathrm{mg} /$ day, p.o.). All sera collected at 9:00-12:00 hr in the morning were kept at $-20^{\circ} \mathrm{C}$ until assayed.

\section{LH and FSH assays}

Serum LH and FSH concentrations were determined by double antibody radioimmunoassays using reagents provided by the National Institute of Arthritis, Diabetes and Digestive and Kidney Disease. NIAMDD-hLH-I-1 (AFP-4345B) and NIAMMD-hFSH-I-1 (AFP-2844B) were used as reference preparations for $\mathrm{LH}$ and $\mathrm{FSH}$, respectively, and their concentrations were expressed as $\mathrm{ng}$ per $\mathrm{ml}$ serum. The within- and betweenassay coefficients of variation were $2.5 \%$ and $8.5 \%$ for $\mathrm{LH}$, and $3.7 \%$ and $9.8 \%$ for $\mathbf{F S H}$, respectively. The limit of detection of the LH assay was $10 \mathrm{ng} / \mathrm{ml}$ while that of the FSH assay was $150 \mathrm{ng} / \mathrm{ml}$.

\section{$\Delta_{1} \Delta_{2}$ ratio}

By defining the first peak of LH or FSH (maximum level before the second administration of LH-RH minus $0 \mathrm{~min}$. level) as $\Delta_{1}$, and the second peak of the hormones (maximum level after the second administration of LH-RH minus $60 \mathrm{~min}$. level) as $\Delta_{2}$, respectively, the $\Delta_{1} \Delta_{2}$ ratio was calculated by dividing $\Delta_{2}$ values by $\Delta_{1}$ values as indicated in Fig. 1. The correlation between the LH- $\Delta_{1} \Delta_{2}$ ratio and serum PRL level in hyperprolactinemia was also investigated.

\section{Statistics}

The data were processed to test the difference between group means for their statistical significance $(\mathrm{P}<0.05$ by one-way analysis of variance and Student's test, or by correlation coefficients computed by least squares analysis.

$\triangle 1$ : Maximum level before the 2nd administration0 min. level

$\triangle 2$ : Maximum level after the 2nd administration$60 \mathrm{~min}$. level

$\triangle 1 \triangle 2$ ratio : $\triangle 2 / \triangle 1$

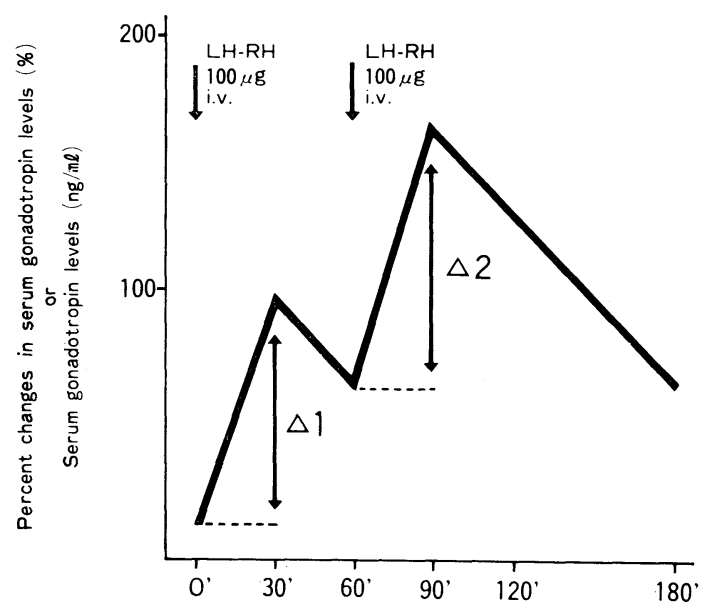

Minutes after first $\mathrm{LH}-\mathrm{RH}$ administration

Fig. 1. Schematic illustration of $\Delta_{1}$ and $\Delta_{2}$ of gonadotropin in two step administration of synthetic LH-RH at 60 minute interval $(100 \%$ $=30 \mathrm{~min}$. levels). 


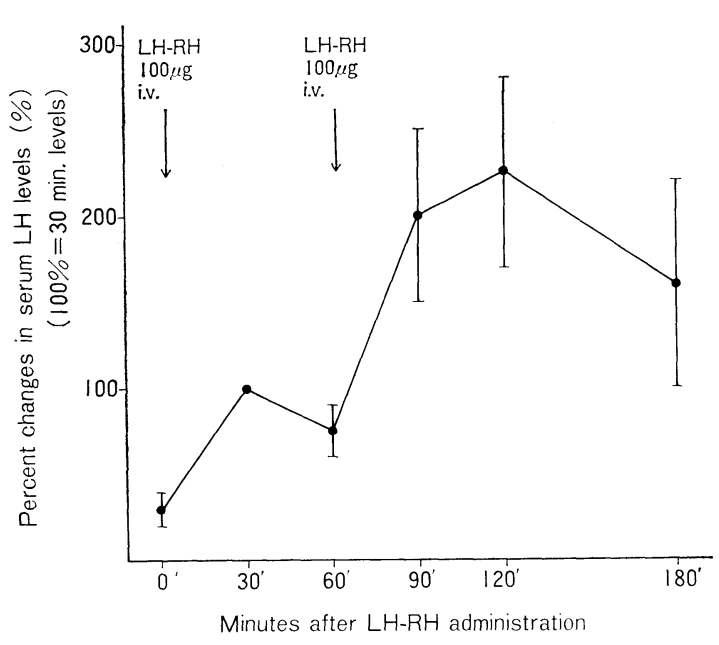

Fig. 2. Two peaks of LH in follicular phase of normal cycling women $(n=6)$ after two step LH-RH administration (mean \pm S.E.).

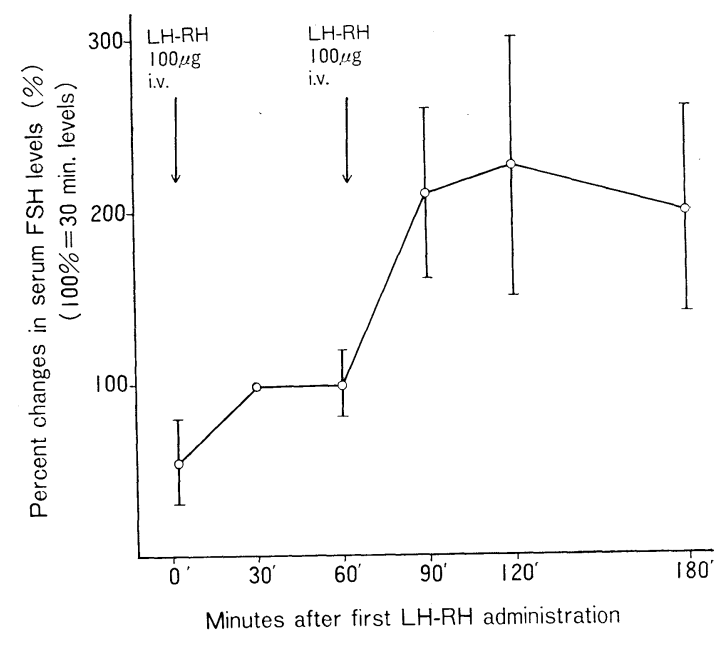

Fig. 3. Two peaks of FSH in follicular phase of normal cycling women $(n=6)$ after two step LH-RH administration (mean \pm S.E.)

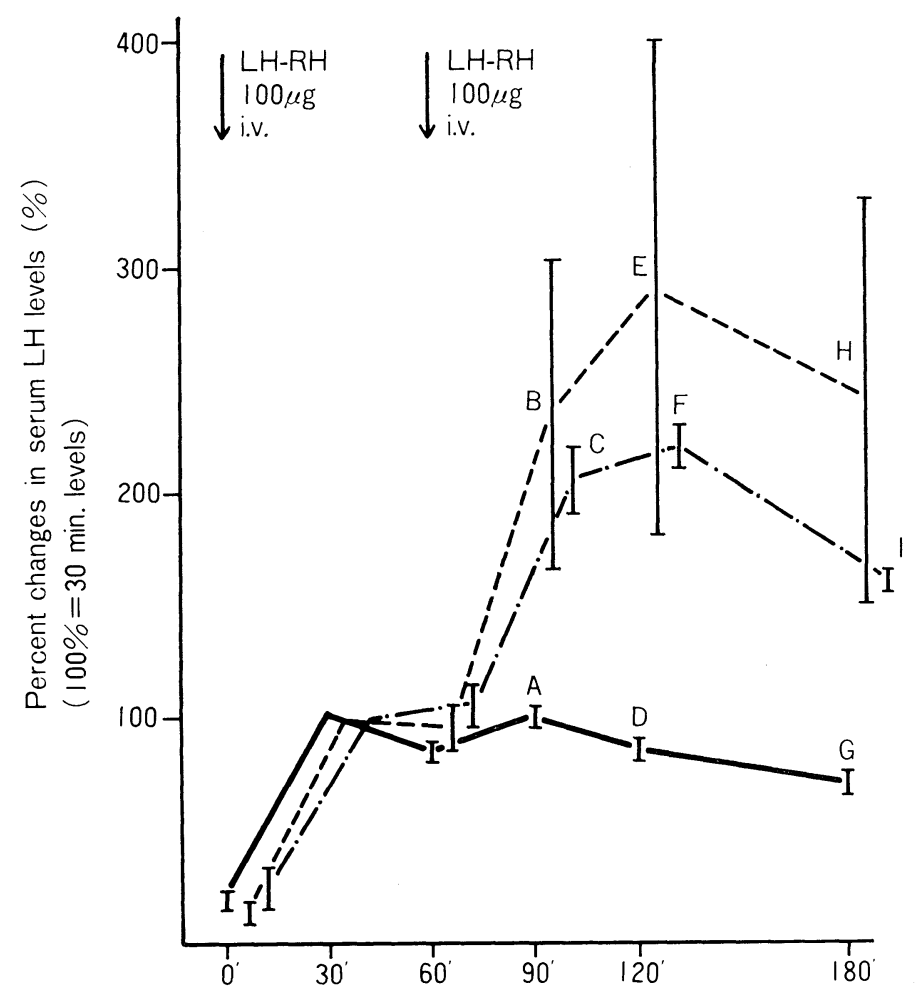

Fig. 4. Serum LH levels in hyperprolactinemia in response to two step LH-RH stimulation (mean \pm S.E.).

Hyperprolactinemia

"PRL $>70 \mathrm{ng} / \mathrm{ml}$ " (n=13)

Relative hyperprolactinemia "30<PRL < $50 \mathrm{ng} / \mathrm{ml}$ " ( $\mathrm{n}=5)$

After treatment with Bromocriptine

"PRL $<25 \mathrm{ng} / \mathrm{ml} "(\mathrm{n}=5)$

$$
\begin{array}{ll}
\mathrm{P}<0.01 & \text { A vs. } B \\
\mathrm{P}<0.01 & \text { A vs. } \mathrm{C} \\
\mathrm{P}<0.01 & \text { D vs. } \mathrm{E} \\
\mathrm{P}<0.01 & \text { D vs. F } \\
\mathrm{P}<0.01 & \text { G vs. } \mathrm{H} \\
\mathrm{P}<0.01 & \text { G vs. I }
\end{array}
$$

Minutes after first $\mathrm{LH}-\mathrm{RH}$ administration 


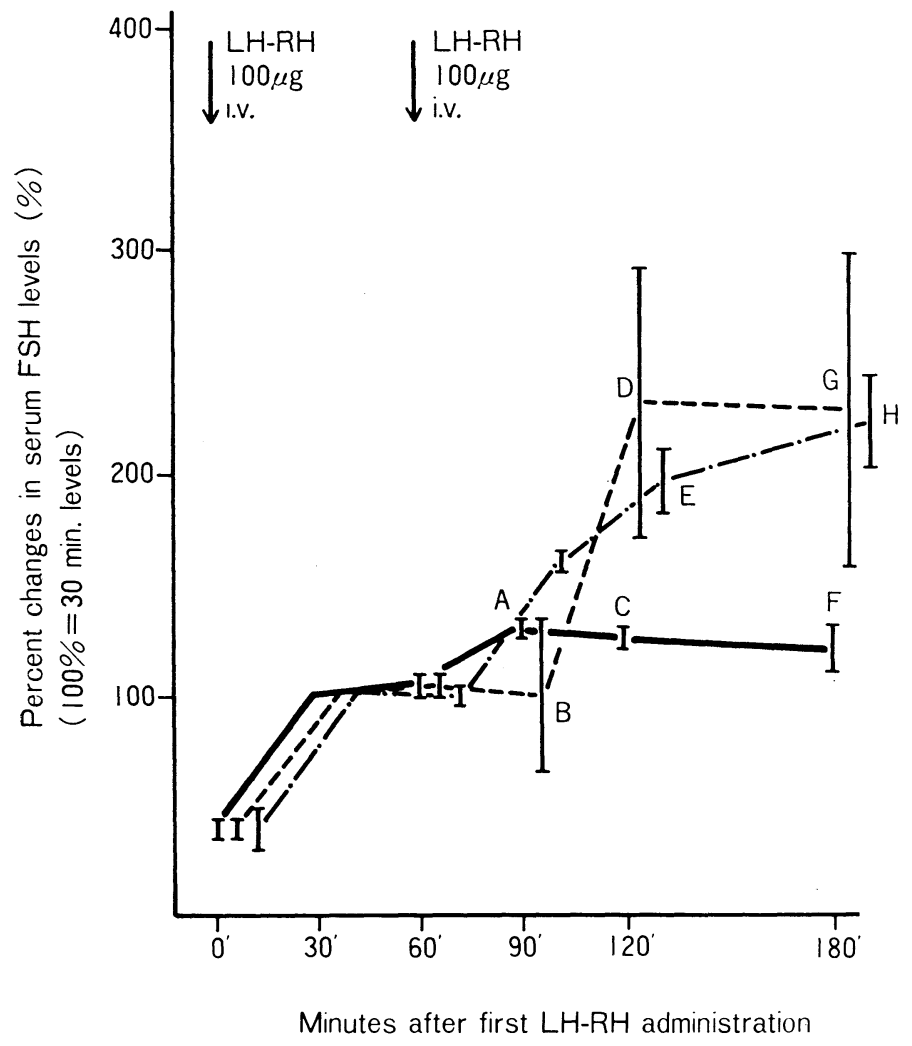

Fig. 5. Serum FSH levels in hyperprolactinemia in response to two step LH-RH stimulation (mean \pm S.E.)

\footnotetext{
Hyperprolactinemia

"PRL > $70 \mathrm{ng} / \mathrm{ml}$ " (n=13)

Relative hyperprolactinemia " $30<\mathrm{PRL}<50 \mathrm{ng} / \mathrm{ml}$ " $(\mathrm{n}=5)$

After treatment with Bromocriptine

"PRL $<25 \mathrm{ng} / \mathrm{ml}$ " ( $n=5$ )

$P<0.05$ A vs. $B$

$P<0.01$ C vs. $D$

$P<0.05 \quad C$ vs. $E$

$P<0.05 \quad F$ vs. $G$

$\mathrm{P}<0.05 \mathrm{~F}$ vs. $\mathrm{H}$
}

\section{Results}

In the follicular phase, normal control women with normal PRL levels $(<20 \mathrm{ng} / \mathrm{ml})$ showed marked first peaks $\left(A_{1}\right)$ of $\mathrm{LH}$ and FSH after the first LH-RH stimulation and enhanced second peaks after the second LH-RH administration (Figs. 2 and 3). The second response of FSH was more moderate than that of LH. Thirteen women with hyperprolactinemia whose serum PRL levels were more than $70 \mathrm{ng} / \mathrm{ml}$ showed a significantly less pronounced priming effect of LH-RH on LH and FSH without significant second peaks $(\mathrm{p}<0.01)$, although the basal levels of these hormones were not apprecia- bly different from those of normal women in the follicular phase (Figs. 4 and 5). In contrast, the priming effect of LH-RH was observed in the group with moderate hyperprolactinemia (30-50 ng PRL/ml). Furthermore, enhanced second peaks of both $\mathrm{LH}$ and FSH were noticed after successful bromocriptine therapy reduced hyperprolactinemia to less than $25 \mathrm{ng} / \mathrm{ml}$. The correlation of the $\Delta_{1} \Delta_{2}$ ratio of serum $\mathrm{LH}$ and PRL concentrations is shown in Fig. 6. As shown in this figure, a significant correlation was observed between them, indicating that the priming effect of LH-RH on gonadotropin can be recovered as serum PRL is reduced to normal. 


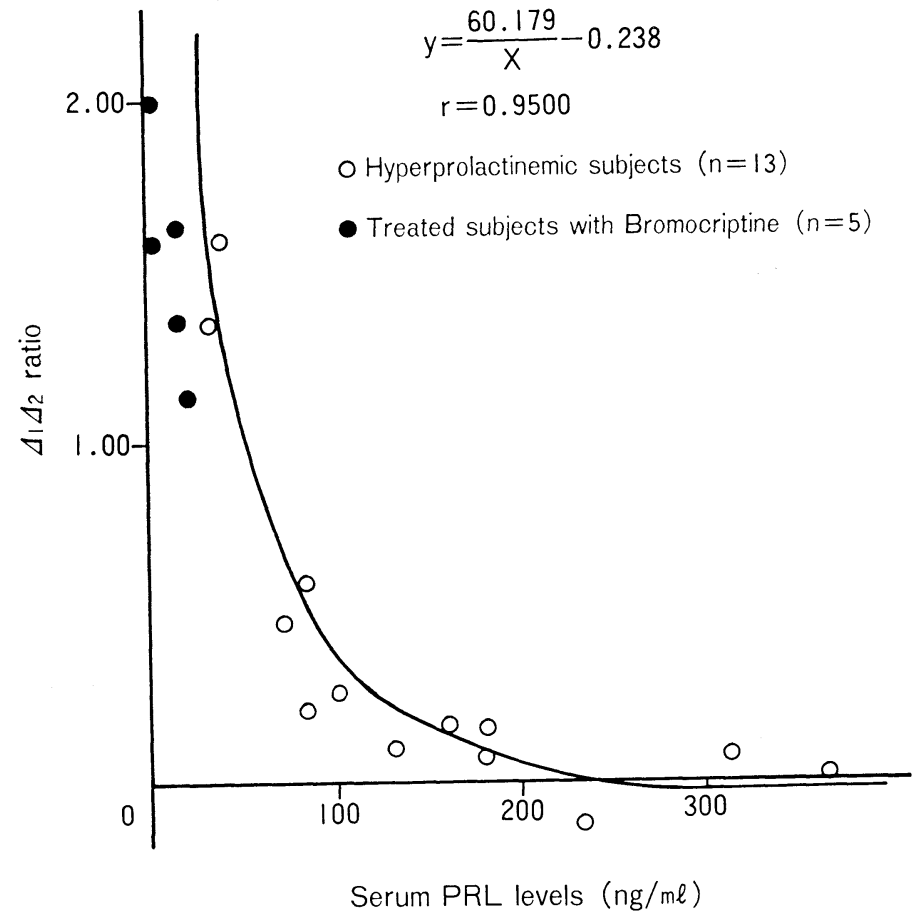

Fig. 6. Statistical analysis on co-relation between $\mathrm{LH} \Delta_{1} \Delta_{2}$ ratio and serum PRL levels in hyperprolactinemia.

\section{Discussion}

Pituitary response to exogenous LH-RH is varied in many species by the mode of stimulation with this peptide. It is well known that single stimulation with $\mathrm{LH}-\mathrm{RH}$ induces secretory peaks of both $\mathrm{LH}$ and FSH 15-30 minutes after its administration either intravenously or intramuscularily. In contrast, continuous infusion of LH-RH (Koninckx et $a l ., 1976)$ to the anterior pituitary induces the first peaks of gonadotropins approximately $30-60 \mathrm{~min}$. after the initiation of exposure, then the discharge of both $\mathrm{LH}$ and FSH gradually declines. If this infusion is continued, the discharge of $\mathrm{LH}$ and FSH again gradually increases and peaks 3-4 hr later. Similarly, intermittent stimulation of the pituitary with $\mathrm{LH}-\mathrm{RH}$ at 60 -minute intervals gives rise to an increase in $\mathrm{LH}$ and FSH initially, followed by more enhanced second peaks of the hormones (Aiyer et al.,
1974) in rats. Wildt et al., (1981) demonstrated that the intermittent administration of LH-RH re-established gonadotropic secretion in rhesus monkeys bearing hypothalamic lesions which abolish endogenous LH-RH production. All these reports suggest that LH-RH not only stimulates the discharge of LH and FSH from the anterior pituitary, but also possibly primes this gland to enhance the responsiveness of the gonadotrophs to further exposure to LH-RH. LHRH stimulation can be done at 60 to 120 minute intervals in human subjects, however all subjects were administered LH-RH at 60 minute intervals in the present study to complete this examination during the morning clinic. The exact mechanism of this priming effect is still unknown, but one possibility is that LH-RH may increase the synthesis of a releasable pool of LH so that the response to the second LH-RH stimulation is increased. Another hypothesis is that the first LH-RH may stimulate the 
production of additional LH-RH receptors on the gonadotrophs with ovarian steroids which are synthesized and released by the first LH-RH (Padmanabhan et al., 1982). Quite recently we demonstrated that the number of secretory granules in the gonadotrophs of the rat anterior pituitary observed electronmicroscopically were significantly decreased after the first administration, but the number increased to the control levels within 60 minutes before the second stimulation, and furthermore, protein synthesis inhibitor suppressed this primary effect in some species (Takahashi, 1986).

In the present study, hyperprolactinemia abolished the priming effect of LH-RH on the gonadotrophs presumably by decreasing the synthesis of the hormones. The reduction of the serum PRL concentration resulted in recovery of the priming effect. It is not clear how the abnormal dopaminergic mechanism acts on the mechanism of synthesis and release of gonadotropins and how normalization of the PRL concentration restored the priming effect, but it is likely that the cyclic center of the hypothalamo-pituitary axis is disordered by the hyperprolactinemic endocrine state, because basal concentrations of $\mathrm{LH}$ and FSH were not influenced by hyperprolactinemia and only the priming effect is suppressed by this endocrine state. By utilizing highly sensitive radioimmunoassay for $\mathrm{LH}-\mathrm{RH}$, we previously demonstrated that peripheral circulatory levels of endogenous LH-RH in matured women were extremely low $(0.99 \pm$ $0.14 \mathrm{pg} / \mathrm{ml}$ serum) (Makino et al., 1980) and pulsatile alteration of this decapeptide in the subjects could not be detected. However, others reported the intermittent discharge of LH-RH into the portal vessel of the hypothalamo-pituitary system in primate (Carmel et al., 1976, Knobil, 1980). Thus, pulsatile stimulation of endogenous LH-RH on the anterior pituitary is a key to maintaining normal pituitary functions of releasing and synthesizing $\mathrm{LH}$ and FSH. Valk et al. (1980) reported that the administration of LH-RH to their patients with isolated gonadotropic deficiency in intermittent doses for 5 days induced a rapid pituitary response, suggesting that the mode of LH-RH secretion controls pubertal maturation.

Although further studies are required to elucidate the details of the mechanism by which the priming effect is exerted, the data indicate that two step stimulation by synthetic LH-RH can be applied to clinical evaluation of the pituitary function and this test is more meaningful than the conventional single LH-RH administration test.

\section{Acknowledgements}

The authors wish to thank the NIH Pituitary Hormone Program for generously donating the human LH, FSH and PRL assay kits. They also wish to thank Ms. Hiroko Ohtsuka for her assistance during the study.

\section{References}

Aiyer, M. S., S. A. Chiappa, G. Fink. A Priming effect of luteinizing hormone releasing factor on the anterior pituitary gland in the female rat. J. Endocr. 62, 573, 1974.

Carmel, P. W., S. Araki, M. Ferin. Pituitary portal blood collection in rhesus monkeys: evidence for pulsatile release of gonadotropinreleasing hormone (Gn-RH). Endocrinology 99, 243, 1976.

Hoff, J. D., B. L. Lasley, C. F. Wang, S. S. C. Yen. The two pools of pituitary gonadotropin: Regulation during the menstrual cycle. J. Clin. Endocrinol. Metab. 44, 302, 1977.

Knobil, E. The neuroendocrine control of the menstrual cycle. Recent Prog. Horm. Res. 36, 53, 1980.

Koninckx, P., R. DeHertogh, W. Heyrs, E. Meulepas, I. Brosens, P. DeMoor. Secretion rates of $\mathrm{LH}$ and $\mathrm{FSH}$ during infusion of LH$\mathrm{FSH} / \mathrm{RH}$ in normal women and in patients with secondary amenorrhea: suggestive evidence for two pools of LH and FSH. J. Clin. Endocrinol. Metab. 43, 159, 1976. 
Lin, B. Y., T. Makino, R. Iizuka. Study on the pituitary function of secreting gonadotropin by LH-RH two step test. Acta Obstet. Gynec. Japan. 34, 1684, 1982.

Makino, T., M. Iwashita, A. Nakayama, R. Iizuka. Study on blood levels of luteinizing hormone beta submit and LH-releasing factor in pregnant women. Keio J. Med. 29, 141151, 1980.

Padmanabhan, V., K. Leung, E. M. Convey. Ovarian steroids modulate the self-priming effect of luteinizing hormone releasing hormone on bovine pituitary cells in vivo. Endocrinology 110, 717, 1982.

Takahashi, M., T. Makino, I. Kamouchi, K.
Fukuoka, T. Seki, R. Iizuka. Physiological significance of the self-priming effect of LH-RH on the anterior pituitary gland. Acta Obstet. Gynec. Japan. 39, 573, 1987.

Valk, T. W., K. P. Corley, R. P. Kelch, J. C. Marshall. Hypogonadotropic hypogonadism: Hormonal responses to low dose pulsatile administration of gonadotropin-releasing hormone. J. Clin. Endocrinol. Metab. 51, 730, 1980.

Wildt, L., A. Hausler, G. Marshall, J. S. Hutchinson, T. M. Plant, P. E. Belchetz, E. Knobil. Frequency and amplitude of gonadotropinreleasing hormone stimulation and gonadotropin secretion in the rhesus monkey. Endocrinology 109, 376, 1981. 